\title{
Prayer nodules
}

\section{Habib ur Rehman MBBS, Nabil A. Asfour MD}

A 59-year-old man had bilateral lichenified, crusted and hemorrhagic nodules over the dorsum of the feet and around the lateral malleoli (Figure 1). The nodules were painless, wellcircumscribed, hyperpigmented and hyperkeratotic. The patient, a Buddhist monk, spent extended periods of time (sometimes days) in a cross-legged sitting position for meditation. He had presented to hospital for an unrelated complaint and was not concerned about the lesions. No treatment was offered.

Prayer nodules occur in response to prolonged and repetitive trauma to the skin. They have been reported to occur on the forehead, knees, ankles and dorsum of the feet. Though rarely as pronounced as those of our patient, prayer marks are relatively common in people who pray regularly. Among Muslim people who pray five times daily (with the dorsa of their feet touching or rubbing against the floor under the weight of the body), prayer marks have been reported in up to $75 \%$ of men and $25 \%$ of women. ${ }^{1}$ A much higher incidence of lichenification and hyperpigmentation was observed in subjects aged 50 years or older. ${ }^{1}$ Histologic findings in prayer nodules are hyperkeratosis, hypergranulosis, acanthosis and mild inflammatory infiltrate in the upper dermis. ${ }^{2}$

Similar callosities can be seen in people who engage in various sports or occupations involving repetitive trauma. Callosities may be found on the ankles of linoleum layers and the knees of plumbers, miners and those who scrape or scrub floors. In musicians, the position of callosities varies according to the instrument used. ${ }^{3}$

The risk of secondary infection, ulceration and bleeding in callosities is generally minimal and dependent on the size and age of the lesion. Larger and older lesions are more prone to complications. ${ }^{1}$ Surgical removal may be performed for cosmetic reasons. Application of $40 \%$ urea white soft paraffin

From the Department of Internal Medicine (Rehman), Regina General Hospital, Regina Qu'Appelle Health Region, Regina; and the Department of Internal Medicine (Asfour), University of Saskatchewan, Saskatoon, Sask.

CMAJ 2010. DOI:10.1503/cmaj.090392 under occlusion followed by curettage may be effective. ${ }^{4}$ Protective clothing (e.g., caps, socks) and use of soft prayer rugs may reduce risk for these lesions. Prayer nodules are benign and do not require investigation, but they can often provide clinicians with helpful information about a patient's cultural background.

This article has been peer reviewed.

Competing interests: None declared.

\section{REFERENCES}

1. Abanmi AA, Al Zouman AY, Al Hussaini H, et al. Prayer marks. Int J Dermatol 2002;41:411-4.

2. Kahana M, Cohen M, Ronnen M, et al. Prayer nodules in Moslem men. Cutis 1986;38:281-2.

3. Gambichler T, Boms S, Freitag M. Contact dermatitis and other skin conditions in instrumental musicians. BMC Dermatol 2004;4:3.

4. English JSC, Fenton DA, Wilkinson JD. Prayer nodules. Clin Exp Dermatol 1984;9:97-8.

Clinical images are chosen because they are particularly intriguing, classic or dramatic. Submissions of clear, appropriately labelled high-resolution images must be accompanied by a figure caption and the patient's written consent for publication. A brief explanation (300 words maximum) of the educational significance of the images with minimal references is required. 